\title{
Study and Practice on Carrying out Teach-Learn-Do Amalgamation in Specialized Course The Automobile Engine Electronic Control Technology
}

\author{
De Ming Yang \\ (Liaoning Jidian Polytechnic, Dandong, Liaoning,China 118009) \\ 171999142@qq.com
}

Keywords: The automobile engine electronic control technology; Teach-Learn-Do amalgamation; Study and practice; Teaching mode

\begin{abstract}
There are still many shortcomings in the teaching of our higher vocational colleges. The author carries on the reform of traditional implementation of specialized course The automobile engine electronic control technology, and introduces the advanced teaching mode "Teach-Learn-Do amalgamation". The paper mainly introduces the research and practice of this teaching mode, and demonstrates the feasibility of applying Teach-Learn-Do amalgamation in the specialized course The automobile engine electronic control technology. What's more, the paper verifies the success and necessity of teaching mode "Teach-Learn-Do amalgamation" in the specialized course $<$ The automobile engine electronic control technology> through the good teaching results after specific implementation.

According to the survey of magazine Auto Fan, in the teaching of automobile major, more than $40 \%$ of higher vocational colleges around the country still adopt the traditional mode, that is to only pass on theoretical knowledge in theory class, then receive practical teaching after completing the theory course. The biggest weakness of the traditional teaching method is theoretical management, in which the theory and practice are disconnected. In the process of learning theory, students feel boring and have no interest, so the study effect is unsatisfactory and the basic theoretical knowledge is weak; the students have high interest in the practical teaching but the ideal results can't be achieved due to lack of solid theoretical knowledge. What's worse, outdated theory is still passed on in some schools, which disconnects the practical teaching contents, and not enough time for practice or old practice equipment, which fall behind the actual technical requirement significantly, leading to scarce practical knowledge.

According to the statistics of human resources and social security, more than $90 \%$ of recruitment units disagree with traditional teaching mode as three-month learning in the repair factory has better results than three-year school learning. In this situation, under the joint efforts of education departments at all levels and department of human resources and social security, the new teaching mode is born at the right moment, which is Teach-Learn-Do amalgamation.
\end{abstract}

\section{The Study on Teach-Learn-Do Amalgamation}

The Definition of Teach-Learn-Do Amalgamation. Generally speaking, Teach-Learn-Do amalgamation is a kind of teaching mode, which is directed by students, guided by teachers, to teach, learn and practice synchronously around certain techniques in practical work[1]. Teach-Learn-Do amalgamation can combine theoretical and practical teaching organically, break traditional subject system and teaching mode, and integrate the teaching resources in accordance with the requirements of vocational education training goal, which embodies the ability-oriented characteristics. The teaching mode can better solve the problem of disconnecting the theoretical and practical teaching, enhance the intuitive nature, fully reflect the subject participation role played by the students, and help improve the teaching quality and cultivate high-quality talents.

Theoretical and Practical Meaning of Teach-Learn-Do Amalgamation. On account of the 
characteristics of higher vocational education, based on the principle of close integration of modern teaching and learning methods as well as theory and practice, studying and drawing lessons from the advanced experience of similar colleges and universities, combined with the project-oriented and task-driven teaching mode, the employment standard in industry and enterprise, and capability requirements in the major of automobile electronic technology[2], the implementation of Teach-Learn-Do amalgamation in the specialized course <The automobile engine electronic control technology> has significant theoretical and practical meaning:

The project parallels the skill training and professional theory knowledge, and links each other closely, which achieves the close combination of theory and practice, and synchronization of reason and sensibility.

The organic combination of theory teaching and skill training can make the students double-check and understand the professional theoretical knowledge and practical application timely. "Teach-Learn-Do amalgamation" narrows the learning goals by focusing one period of teaching time and emphasizing one task module. From "structure", "operating principle" to "maintenance and troubleshooting", the students can form a complete recognition to the system of task module coherently and in line with the cognitive logic in a relatively short period of time. The teaching mode applies the ways of sense memory, understanding memory and movement memory to promote memory, so students can quickly develop comprehensive knowledge system of the learning objects in the brain.

Repeated crossover of theoretical learning and skill training and constantly updated content are fresh to the students. Skill training guided by theory can make students feel truly learn the skills, increase self-confidence and speed up the process of skill formation. Moreover, under the guidance professional technical theory, the quality of practice teaching is ensured as well as the good condition of teaching equipments.

"Teach-Learn-Do amalgamation" enhance the direct contact of teachers and students and build a good relationship between teachers and students, which makes the teacher understand the degree of students mastering professional knowledge and skills more intuitively. According to the actual situation of students, from different angles, using different methods, students are taught case by case to meet the needs of students in different levels.

"Teach-Learn-Do amalgamation" sets higher demands for course teachers, making them constantly improve their professional theoretical knowledge and practical operating ability and become "compound" teachers. Based on their own specific situations, the teachers learn from others' strong points to offset their weakness, improve their own professional abilities, the teaching level and quality, and enhance their sense of responsibility so as to improve the teaching effect.

\section{The Implementation of Teach-Learn-Do Amalgamation in The Specialized Course The Automobile Engine Electronic Control Technology}

The Stage of Research and Data Preparation, Consolidating The Basis for Project Implementation. The project team inspected the state-level demonstration higher vocational colleges, such as Wuxi Vocational and Technical College and Nanjing Traffic Junior College, and researched the cultivation schemes, curriculums, experiment courses and training courses of the majors related with automobile. The team visited and inspected the Dalian Panasonic automobile electronics technology Co., Ltd, Shitong electronic technology Co., Ltd, Changhong automobile repair factory in succession, understood the professional skill requirements for special skilled talents majored in automobile electronic technology with high quality for enterprises and employment standard[3]. The project team is organized for in-depth research and analysis, and reviewing a large number of relevant literature in order to demonstrate the feasibility of the teaching mode of Teach-Learn-Do amalgamation in the specialized course <The automobile engine electronic control technology>, which lays a solid theoretical and practical basis for the implementation of this project. 
To Improve The Construction of Automobile Engine Electronic Control Training Room---training Room Construction of Teach-Learn-Do Amalgamation. In order to implement the teaching mode of Teach-Learn-Do amalgamation in the specialized course The automobile engine electronic control technology[4], the first is to give up the traditional way of allocating the training equipment according to the major, and bring together the electronic control gasoline engine training platform, starting system demonstrator, charging system demonstrator, automobile fuel system demonstrator, engine electronic control system demonstrator and Santana engine anatomy demonstrator into the training room for Teach-Learn-Do amalgamation. In this way, the engine starting system, the electric generator power supply system, the fuel supply system, air supply system, engine electronic control system, engine structure, engine working process and engine working principle are formed into one complete stereo structure; the preparation of the complete training equipment helps students establish complete knowledge system. The second is the transformation of electric power system in the training room; most training equipments require single-phase, and some require three-phase as the power source to drive the three-phase AC asynchronous motor. The third is to install multimedia equipment, which coordinates the teaching through playing the teaching materials such as PPT, video and animation. The last is to arrange the student chairs reasonably in order to bring close the relationship between students and teachers and improve the teaching effect of the Teach-Learn-Do amalgamation[5].

To Promote The Project Development of The Training Equipments such as Automobile Engine Training Platform, Automobile Engine Electronic Control System Demonstrator and Automobile Fuel Supply System Demonstrator. The project development of training equipment should pay attention to the logic, coherence and practicability of the engine working process[6]. Concerning the teaching mode of Teach-Learn-Do amalgamation, lots of research, integration and sorting are needed for developing corresponding teaching project of the specialized course of The automobile engine electronic control technology. In the teaching process of The automobile engine electronic control technology, it involves the contents learned before by students in the courses such as Automobile mechanics, Automotive electronic technology, Electronic equipments in automobile, etc. However, the knowledge of previous courses is unsatisfactory in the teaching process of The automobile engine electronic control technology because of long interval, weak knowledge, not forming complete knowledge system, etc. The development of teaching project can integrate the course content and help students establish complete knowledge system when finish the study of The automobile engine electronic control technology. For example, developing the project of Start control of automobile engine can involve the engine starting system demonstrator related with the course Automotive electronic technology and Electronic equipments in automobile, Santana engine anatomy demonstrator related with the course Automobile mechanics, and electronic control gasoline engine demonstrator related with the course The automobile engine electronic control technology; developing the project of Working process of automobile engine can involve the Santana engine anatomy demonstrator related with the course Automobile mechanics, automobile fuel system demonstrator related with the course Automotive electronic technology and Electronic equipments in automobile, and engine electronic control system demonstrator and electronic control gasoline engine demonstrator related with the course The automobile engine electronic control technology. In this way, in the teaching process of The automobile engine electronic control technology, it can integrate all the course contents and help students establish complete knowledge system.

\section{To Achieve The Teaching Mode of Teach-Learn-Do Amalgamation in The Specialized Course The Automobile Engine Electronic Control Technology}

The practical base is the training room for Teach-Learn-Do amalgamation, and the theoretical base is the teaching project of engine electronic control technology; the aim is how to achieve the teaching mode of Teach-Learn-Do amalgamation in the specialized course The automobile engine electronic 
control technology. This is process of "research-try-reflection-promotion" in the actual teaching process; try while researching, reflect while trying, and promote while reflecting[7]. The project takes two school years for freshmen and sophomores majored in automobile electronic technology to study the specialized course The automobile engine electronic control technology, and achieves excellent teaching effects through the teaching mode of Teach-Learn-Do amalgamation.

The specialized course The automobile engine electronic control technology practices Teach-Learn-Do amalgamation. In the first school year, the specialized course The automobile engine electronic control technology for sophomore majored in automobile electronic technology will be completed in the training room for Teach-Learn-Do amalgamation, the actual problems can be found in the actual teaching process "research-try-reflect-promotion" [8]. At the same time, the freshmen majored in automobile electronic technology will get familiar with the training room for Teach-Learn-Do amalgamation while completing the course as sophomores. In the second school year, we make in-depth analysis to the simulated situational teaching model, task-driven teaching mode, heuristic teaching mode, and game-interact teaching mode based on the teaching experience of the sophomores, and form the teaching mode suitable for the course The automobile engine electronic control technology[9]. When students upgrade from freshmen, they will continue the study in the training room for Teach-Learn-Do amalgamation to finish the course The automobile engine electronic control technology; innovative teaching mode of Teach-Learn-Do amalgamation will be adopted for learning enthusiasm and effect. Theoretical knowledge and practical skills have been greatly improved; the students achieved good results in professional skills contest and national patent filing.

\section{Conclusion}

In conclusion, Teach-Learn-Do amalgamation has combined the theoretical teaching and practical teaching organically[10], broke the traditional subject system and teaching mode, and reintegrated teaching materials based on the cultivation objectives of vocational education. This paper introduces in detail the reform process of the course The automobile engine electronic control technology. Through researching the Teach-Learn-Do amalgamation, the teaching mode is adopted in the course The automobile engine electronic control technology, which deepens the curriculum reform; applying the teaching mode into the entire major of automobile electronic technology brings the higher vocational education level into a higher level.

\section{Acknowledgements}

Project of Liaoning Mechatronics Polytechnic College; Project name: study and practice on diversifying implementation of talent cultivation named as "excellent technician"; Project number: JYLX2015001

\section{References}

[1] W.Z. Gong: Journal of Wuxi Vocational and Technical College, Vol. 10 (2011) No.1, p.87. (In Chinese)

[2] L.D. Chen and K.K. Chen: Journal of Liaoning higher vocational college, Vol. 9 (2007) No.2, p.39. (In Chinese)

[3] Y.F. Cui and Y. Li: Vocational technology, Vol. 109 (2009) No.9, p.29. (In Chinese)

[4] H. Yu: Journal of Huanggang vocational technical college, Vol. 13 (2011) No.8, p.16. (In Chinese) 
[5] Y.J. Ma: Journal of Normal College of Qingdao University, Vol. 26 (2009) No.3, p. 22. (In Chinese)

[6] Information on http://en.wikipedia.org/wiki/Engine_control_unit

[7] Z.Zhou:International Conference on Education Science and Management Engineering(BeiJing.China, August 16,2011). Vol. 1, p.988.

[8] Information on http://bbg.handsbrain.com/wciyu/entry/390391.

[9] J. Dewey: Teaching and Thinking (The Commercial Press, China 1936).

[10] B.L. Dong: Education on the Tao Xingzhi (People's Education Press, China 1991 ) 